\title{
Stability of quad-helix/crib therapy in dentoskeletal open bite: A long-term controlled study
}

\author{
Manuela Mucedero, ${ }^{\text {a }}$ Lorenzo Franchi, ${ }^{b}$ Veronica Giuntini, ${ }^{c}$ Andrea Vangelisti, ${ }^{c}$ James A. McNamara, Jr, ${ }^{d}$ \\ and Paola Cozza ${ }^{\mathrm{e}}$ \\ Rome and Florence, Italy, and Ann Arbor, Mich
}

\begin{abstract}
Introduction: The purpose of this study was to evaluate the long-term stability of quad-helix/crib treatment in subjects with dentoskeletal open bite. Methods: Twenty-eight subjects (11 boys, 17 girls; mean age, $8.2 \pm 1.3$ years) were treated consecutively with quad-helix/crib appliances. The patients were reevaluated at the end of active treatment with the quad-helix/crib (mean age, $9.7 \pm 1.6$ years) and at least 5 years after the completion of treatment (mean age, $14.6 \pm 1.9$ years). A control group of 20 untreated subjects with the same dentoskeletal disharmony was used for the statistical comparison (Mann-Whitney $U$ test). Results: In the long term, the quad-helix/crib group showed a significant reduction in the ANB angle $\left(-1.3^{\circ}\right)$, a downward rotation of the palatal plane $\left(1.8^{\circ}\right)$, a greater increase in overbite $(2.1 \mathrm{~mm})$, and a decrease in overjet $(-1.5 \mathrm{~mm})$ when compared with the controls. Conclusions: In the long term, the use of the quad-helix/crib appliance led to successful outcomes in about $93 \%$ of the patients considered. Correction of dentoskeletal open bite was associated with a clinically significant downward rotation of the palatal plane. (Am J Orthod Dentofacial Orthop 2013;143:695-703)
\end{abstract}

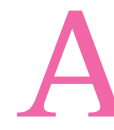

nterior open bite is characterized by a localized absence of occlusion between the incisal edges of the maxillary and mandibular teeth when the remaining teeth are in occlusion. ${ }^{1,2}$ This malocclusion occurs because of interferences during normal dental eruption and alveolar development. Several factors are involved in the etiology of anterior open bite. $^{3-6}$ Thumb sucking and increased vertical

\footnotetext{
${ }^{a}$ Research fellow, Department of Orthodontics, University of Rome "Tor Vergata," Rome, Italy.

${ }^{\mathrm{b}}$ Assistant professor, Department of Orthodontics, University of Florence, Florence, Italy; Thomas M. Graber Visiting Scholar, Department of Orthodontics and Pediatric Dentistry, School of Dentistry, University of Michigan, Ann Arbor. 'Research associate, Department of Orthodontics, Università degli Studi di Firenze, Firenze, ltaly.

${ }^{\mathrm{d}}$ Thomas M. and Doris Graber Endowed Professor of Dentistry, Department of Orthodontics and Pediatric Dentistry, School of Dentistry; research professor, Center for Human Growth and Development, University of Michigan, Ann Arbor. eProfessor and chair, Department of Orthodontics, University of Rome "Tor Vergata," Rome, Italy.

The authors report no commercial, proprietary, or financial interest in the products or companies described in this article.

Reprint requests to: Lorenzo Franchi, Dipartimento di Odontostomatologia, Università degli Studi di Firenze, Via del Ponte di Mezzo, 46-48, 50127 Firenze, ltaly; e-mail, lorenzo.franchi@unifi.it.

Submitted, September 2012; revised and accepted, January 2013. 0889-5406/\$36.00

Copyright (C) 2013 by the American Association of Orthodontists.

http://dx.doi.org/10.1016/j.ajodo.2013.01.010
}

skeletal relationships are significant risk factors for the establishment of an anterior open bite. ${ }^{6,7}$ Subjects with dentoskeletal open bite and sucking habits often have concomitant transverse discrepancies. ${ }^{8}$ Many authors have emphasized that a skeletal open bite should be treated early in the mixed dentition to allow for normal development of the anterior dentoalveolar region..$^{9-11}$

Various treatment approaches can be found in the literature with regard to early treatment of anterior open bite. ${ }^{12-18}$ The elimination of persisting sucking habits and the control of the vertical dimension must be therapeutic objectives. The correction of maxillary constriction is an additional target for treatment in patients with open bite. ${ }^{19}$

The use of a palatal crib has been proposed as an excellent treatment option, because it prevents thumb or pacifier sucking, as well as tongue thrust. ${ }^{3,20-23}$ According to Haryett et al, ${ }^{22}$ the palatal crib is effective for the elimination of a thumb-sucking habit in $85 \%$ to $90 \%$ of subjects. Studies reporting the success of early treatment in subjects with anterior open bite when compared with a well-matched control group, however, are scarce in the literature. Only 2 studies have incorporated untreated controls with the same type of dentoskeletal disharmony, but they were confined to short-term observations. ${ }^{24,25}$ The authors of both 
studies analyzed the effects of a removable palatal crib associated with a vertical-pull chincup; this treatment protocol did not produce significant changes in the skeletal maxillary and mandibular components. The results of both studies showed that the effects of therapy primarily were dentoalveolar.

A proposed treatment protocol aimed to eliminate the thumb-sucking habit and to correct both the anterior open bite and the maxillary transverse deficiency in growing high-angle subjects is a quad-helix $(\mathrm{Q}-\mathrm{H})$ appliance with the addition of a palatal crib $(\mathrm{Q}-\mathrm{H} / \mathrm{C}){ }^{17,25}$ When compared with the effects of a removable appliance (open-bite bionator or removable palatal crib), the $\mathrm{Q}-\mathrm{H} / \mathrm{C}$ appliance was shown to be significantly more effective in the improvement of overbite in the short term. ${ }^{26,27}$ The treatment and posttreatment effects of a $\mathrm{Q}-\mathrm{H} / \mathrm{C}$ appliance showed a clinical effectiveness in correcting the dental open bite of $85 \%$ of the patients after a follow-up of 2 years. ${ }^{28}$ This favorable result was associated with clinically significant improvement in the maxillomandibular vertical skeletal relationships. No data, however, are available in the literature about the outcomes of the $\mathrm{Q}-\mathrm{H} / \mathrm{C}$ appliance reevaluated at a follow-up of at least 5 years.

The purpose of this study, therefore, was to evaluate the long-term stability of $\mathrm{Q}-\mathrm{H} / \mathrm{C}$ treatment in subjects with thumb-sucking habits and anterior dentoskeletal open bite. Both active treatment and posttreatment effects were analyzed in consecutively treated patients, and these results were compared with the growth changes in an untreated control group with the same dentoskeletal disharmony during a follow-up period of at least 5 years.

\section{MATERIAL AND METHODS}

The Q-H/C sample comprised 28 subjects ( 17 girls, 11 boys) who were treated consecutively at the Department of Orthodontics at the University of Rome "Tor Vergata" or in a private orthodontic practice in Rome. Lateral cephalograms of treated patients were analyzed regardless of treatment results. Each patient had the following features: thumb-sucking habit before treatment; negative overbite; constricted maxillary arch as consequence of thumb sucking; full eruption of first permanent molars and permanent incisors (to prevent the "pseudo-open bite" due to undererupted permanent incisors) ${ }^{29}$; no permanent teeth extracted before or during treatment; 3 consecutive lateral cephalograms of good quality with adequate landmark visualization and minimal or no rotation of the head, taken before treatment (T1), at the end of the active treatment with the $\mathrm{Q}-\mathrm{H} / \mathrm{C}$ (T2), and at a follow-up observation at least 5 years after the completion of treatment (T3); and treatment with the $\mathrm{Q}-\mathrm{H} / \mathrm{C}$ appliance for at least 12 months. $^{17}$

All subjects were at a prepubertal stage of skeletal maturity according to the cervical vertebral maturation method (CS 1 or CS 2 ) at T1. ${ }^{30}$ The overall observation period was $6.4 \pm 1.4$ years, which included a followup period of at least 5 years during which the $\mathrm{Q}-\mathrm{H} / \mathrm{C}$ patients were treated with fixed appliances. No active biomechanics or vertical elastics to extrude the incisors were applied during fixed appliance therapy. No intraoral Class ll elastics were used.

All subjects had reached postpubertal skeletal maturity at T3 (CS 4-6). The stages of cervical vertebral maturation were determined by a calibrated examiner (L.F.) trained in this method. All patients were in the permanent dentition at $\mathrm{T} 3$.

A control group of 20 subjects ( 10 girls, 10 boys) with anterior open bite was retrieved from the archives of the University of Michigan Growth Study and the Denver Child Growth Study. The control group matched the $\mathrm{Q}-\mathrm{H} / \mathrm{C}$ group for negative overbite at T1, chronologic age, and skeletal maturation at the various time periods and for the duration of intervals.

The mean ages at the 3 time periods in both the $\mathrm{Q}-\mathrm{H} / \mathrm{C}$ and control groups and the duration of either treatment or observation intervals are given in Table 1.

The Q-H appliance used in this study was made of 0.036-in stainless steel wire soldered to bands on the second deciduous molars or the first permanent molars (Fig). ${ }^{25}$ The lingual arms of the appliance extended mesially to the deciduous canines or to the permanent incisors. The anterior helices were brought as far forward on the palate as possible. Spurs to prevent thumb sucking were formed from 3 segments of 0.036-in stainless steel wire soldered to the anterior bridge of the $\mathrm{Q}-\mathrm{H}$. The wire segments were inclined lingually to prevent impingement on the sublingual mucosa. ${ }^{25}$ Activation of the Q-H was equivalent to the buccolingual width of 1 molar. The appliance was reactivated once or twice during treatment to achieve overcorrection of the transverse relationships.

The $\mathrm{T} 1, \mathrm{~T} 2$, and $\mathrm{T} 3$ cephalograms were hand traced by 1 investigator (V.G.) and then verified for landmark location by a second investigator (L.F.). Any disagreements were resolved by retracing the landmark or structure to the satisfaction of both observers. Cephalometric software (Viewbox, version 3.0; dHAL Software, Kifissia, Greece) was used for a customized digitization regimen that contained 21 variables (11 linear, 10 angular). The magnification factor of the cephalograms was standardized at $8 \%$. 
Table I. Demographics of the groups

\begin{tabular}{|c|c|c|c|c|}
\hline \multirow{2}{*}{$\begin{array}{c}\text { Chronologic } \\
\text { age }(y)\end{array}$} & \multicolumn{2}{|c|}{$Q-H / C$ group $(n=28)$} & \multicolumn{2}{|c|}{ Control group $(n=20)$} \\
\hline & Mean & $S D$ & Mean & $S D$ \\
\hline $\mathrm{T} 1$ & 8.2 & 1.3 & 8.1 & 0.4 \\
\hline T2 & 9.7 & 1.6 & 9.8 & 0.4 \\
\hline T3 & 14.6 & 1.9 & 14.5 & 0.7 \\
\hline T1-T2 & 1.5 & 0.4 & 1.7 & 0.4 \\
\hline $\mathrm{T} 2-\mathrm{T} 3$ & 4.9 & 1.3 & 4.7 & 0.6 \\
\hline T3-T1 & 6.4 & 1.4 & 6.4 & 0.7 \\
\hline
\end{tabular}

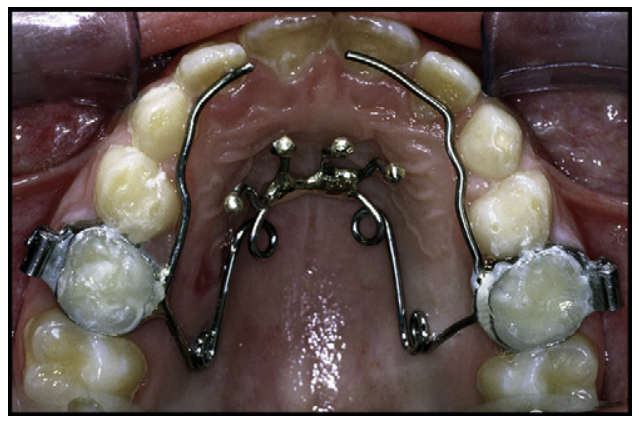

Fig. Intraoral view of the $\mathrm{Q}-\mathrm{H} / \mathrm{C}$ in place.

\section{Statistical analysis}

Descriptive statistics (mean differences and standard deviations) were calculated for all cephalometric measurements at $\mathrm{T} 1$, and for the changes from $\mathrm{T} 1$ to T2, T2 to T3, and T1 to T3 in both groups.

The homogeneity between the $\mathrm{Q}-\mathrm{H} / \mathrm{C}$ and control groups for skeletal maturity at each observation time and mean duration of observation intervals allowed for comparisons without annualizing the data. Matching between treated and control subjects was tested also by means of propensity score analysis. ${ }^{31}$ This matching protocol in observational studies allows researchers to mimic randomization by creating a sample of subjects who did not receive treatment comparable on all observed covariates with the sample of subjects who received treatment. ${ }^{32,33}$ The program "psmatching"33 (available at http://sourceforge.net/projects/psmspss/ files) was used to calculate propensity scores and to test matching between the treated and control samples (SPSS version 21.0; IBM, Armonk, NY). Propensity scores were calculated for some clinically relevant covariates (Wits, Frankfort horizontal to palatal plane, palatal plane to mandibular plane, and overbite) whereas all other variables were entered as additional covariates. An overall balance chi-square test developed by Hansen and Bowers ${ }^{34}$ was applied to test group matching. This test examines all covariates that were used to estimate the propensity scores and all variables that were defined as additional covariates.
Changes in the 2 groups were compared by nonparametric tests, since normal distribution (Kolmogorov-Smirnov test) or equality of variances (Levene test) could not be assessed for all variables. In general, parametric tests are more powerful than nonparametric statistics. However, the assumptions required for parametric tests are particularly important when sample sizes are small, with small usually thought to be fewer than 30 in each group; if the assumptions cannot be verified, then nonparametric methods should be used. ${ }^{35}$

Before making the comparisons of the longitudinal changes, significant differences between the craniofacial starting forms at $\mathrm{T} 1$ were assessed with the Mann-Whitney $\mathrm{U}$ test between the $\mathrm{Q}-\mathrm{H} / \mathrm{C}$ and control groups. To assess the differences between the $\mathrm{Q}-\mathrm{H} / \mathrm{C}$ and control groups with regard to T1 to T2, T2 to T3, and overall $\mathrm{T} 1$ to $\mathrm{T} 3$ changes, Mann-Whitney $\mathrm{U}$ tests $(P<0.05 ; P<0.01$; and $P<0.001)$ were used. Chi-square tests with the Yates correction were performed to compare the prevalence rates of correction of anterior open bite in the 2 groups at T2 and T3. The correction of anterior open bite at the dentoalveolar level was considered to be obtained when the overbite measurement was equal to or greater than $0 \mathrm{~mm}$.

The data were analyzed with statistical software (SPSS 21.0 and SigmaStat version 3.5; Systat Software, Point Richmond, Calif). Statistical significance was tested at $P<0.05$. The power of the study was 0.91 for an alpha level of 0.05 and an effect size equal to $1^{36}$ for the clinically relevant variable palatal plane to mandibular plane angle, as derived from a previous study. ${ }^{28}$

To test the reliability of the measurements, 20 lateral cephalograms randomly selected from various subjects in the study were retraced and remeasured by the same examiner (V.G.) after a 1-month interval. ${ }^{37}$ No systematic error was found with the Wilcoxon signed rank test.

Random errors were estimated with Dahlberg's formula. ${ }^{38}$ The errors for linear measurements ranged from $0.1 \mathrm{~mm}$ for pogonion to nasion perpendicular, to $1.2 \mathrm{~mm}$ for condylion-gonion. The errors for angular measurements ranged from $0.4^{\circ}$ for ANB angle, to $1.4^{\circ}$ for interincisal angle.

\section{RESULTS}

Analysis of the starting forms (Table ll) showed that the $\mathrm{Q}-\mathrm{H} / \mathrm{C}$ and the control groups had no statistically significant differences in craniofacial characteristics at T1. The only exception was a significantly longer ramus length (Co-Go) at T1 in the Q-H/C group. For the dentoskeletal features at $\mathrm{T} 1$, the vertical skeletal relationship was increased, and the sagittal intermaxillary relationship was skeletal Class 11 in both groups. The overall matching 
Table II. Comparison of starting forms (T1)

\begin{tabular}{|c|c|c|c|c|c|c|}
\hline \multirow[b]{2}{*}{ Cephalometric measurement } & \multicolumn{2}{|c|}{$Q-H / C$ group $(n=28)$} & \multicolumn{2}{|c|}{ Control group $(n=20)$} & \multirow[b]{2}{*}{ Difference } & \multirow[b]{2}{*}{ Significance } \\
\hline & Mean & $S D$ & Mean & $S D$ & & \\
\hline \multicolumn{7}{|l|}{ Maxillary skeletal } \\
\hline SNA $\left(^{\circ}\right)$ & 82.1 & 2.9 & 80.7 & 3.2 & 1.4 & NS \\
\hline Point A-nasion perp (mm) & 2.4 & 2.7 & 1.1 & 3.0 & 1.3 & NS \\
\hline \multicolumn{7}{|l|}{ Mandibular skeletal } \\
\hline $\operatorname{SNB}\left({ }^{\circ}\right)$ & 76.8 & 3.2 & 75.4 & 2.0 & 1.4 & NS \\
\hline Pg-nasion perp (mm) & -5.5 & 6.6 & -8.5 & 4.0 & 3.0 & NS \\
\hline Co-Gn (mm) & 106.3 & 6.5 & 104.3 & 3.9 & 2.0 & NS \\
\hline \multicolumn{7}{|l|}{ Maxillary/mandibular } \\
\hline ANB $\left({ }^{\circ}\right)$ & 5.3 & 2.4 & 5.4 & 2.0 & -0.1 & NS \\
\hline Wits (mm) & -1.6 & 2.7 & -1.5 & 2.6 & -0.1 & NS \\
\hline \multicolumn{7}{|l|}{ Vertical skeletal } \\
\hline $\mathrm{FH}-\mathrm{PP}\left({ }^{\circ}\right)$ & -3.1 & 3.4 & -3.4 & 2.8 & 0.3 & NS \\
\hline $\operatorname{MPA}\left({ }^{\circ}\right)$ & 28.5 & 4.2 & 27.9 & 4.4 & 0.6 & NS \\
\hline PP-mandibular plane $\left({ }^{\circ}\right)$ & 31.5 & 4.9 & 31.3 & 4.0 & 0.2 & NS \\
\hline ANS-Me (mm) & 65.1 & 5.7 & 64.9 & 4.1 & 0.2 & NS \\
\hline Co-Go (mm) & 49.3 & 3.3 & 47.2 & 3.5 & 2.1 & * \\
\hline Gonial angle $\left({ }^{\circ}\right)$ & 131.7 & 5.1 & 130.2 & 4.2 & 1.5 & NS \\
\hline \multicolumn{7}{|l|}{ Interdental } \\
\hline Overjet (mm) & 2.8 & 2.9 & 3.6 & 1.8 & -0.8 & NS \\
\hline Overbite (mm) & -3.3 & 1.6 & -2.2 & 2.3 & -1.1 & NS \\
\hline Interincisal angle $\left({ }^{\circ}\right)$ & 122.0 & 9.7 & 125.7 & 11.0 & -3.7 & NS \\
\hline Molar relationship (mm) & 0.4 & 1.9 & 0.8 & 1.3 & -0.4 & NS \\
\hline \multicolumn{7}{|l|}{ Maxillary dentoalveolar } \\
\hline U1-Point A vert (mm) & 4.4 & 2.3 & 3.8 & 1.8 & 0.6 & NS \\
\hline $\mathrm{U} 1-\mathrm{FH}\left({ }^{\circ}\right)$ & 117.0 & 7.8 & 114.3 & 6.8 & 2.7 & NS \\
\hline \multicolumn{7}{|l|}{ Mandibular dentoalveolar } \\
\hline L1-Point A Pg (mm) & 2.1 & 2.1 & 1.9 & 2.2 & 0.2 & NS \\
\hline L1-MPA $\left(^{\circ}\right)$ & 93.1 & 6.0 & 92.6 & 7.1 & 0.5 & NS \\
\hline
\end{tabular}

between the treated and control groups was assessed further with propensity scores. The chi-square balance test was not statistically significant (chi-square $=28.154$; $P=0.081$ ), thus indicating good overall balance between the 2 groups.

The statistical comparisons of the T1 to T2 changes (Table III) showed no statistically significant differences between the Q-H/C and control samples for any maxillary or mandibular skeletal measurements in the sagittal plane. For the vertical skeletal measurements, the $\mathrm{Q}-\mathrm{H} / \mathrm{C}$ group exhibited greater downward rotation of the palatal plane than did the control group (1.9 mm). A significant effect of therapy was found for the dentoalveolar variables. The $\mathrm{Q}-\mathrm{H} / \mathrm{C}$ group showed a significantly greater increase in overbite $(2.2 \mathrm{~mm}$ more than the control group) associated with $5.7^{\circ}$ of lingual tipping of the mandibular incisors relative to the mandibular plane with respect to the controls.

After active treatment (T2), the prevalence rates for correction of overbite were $86 \%$ (24 subjects) in the Q-H/C group and 50\% (10 subjects) in the control group. The comparison was statistically significant (chi-square $=5.58 ; P=0.018$ ).

No significant differences in posttreatment changes (T2-T3) were found between the $\mathrm{Q}-\mathrm{H} / \mathrm{C}$ and control groups (Table IV).

The evaluation of the overall treatment changes from T1 to T3 (Table V) showed significant differences in the sagittal skeletal relationships. The intermaxillary skeletal relationships showed a significant reduction in the ANB angle of $-1.3^{\circ}$ in the $\mathrm{Q}-\mathrm{H} / \mathrm{C}$ group compared with the control group. Vertical skeletal variables maintained a significant improvement in the $\mathrm{Q}-\mathrm{H} / \mathrm{C}$ group vs the controls (Frankfort horizontal to palatal plane, $1.8^{\circ}$; palatal plane to mandibular plane, $-2.2^{\circ}$ ). Overbite had a significantly greater increase in the $\mathrm{Q}-\mathrm{H} / \mathrm{C}$ group (2.1 $\mathrm{mm}$ more than the control group), and a significant decrease was found for overjet in the $\mathrm{Q}-\mathrm{H} / \mathrm{C}$ group vs the controls $(-1.5 \mathrm{~mm})$.

At the follow-up observation (T3), 26 subjects (93\%) in the $\mathrm{Q}-\mathrm{H} / \mathrm{C}$ group showed a corrected overbite. This prevalence rate was significantly greater than that in the 
Table III. Comparison of changes during treatment (T1-T2)

\begin{tabular}{|c|c|c|c|c|c|c|}
\hline \multirow[b]{2}{*}{ Cephalometric measurement } & \multicolumn{2}{|c|}{$Q-H / C$ group $(n=28)$} & \multicolumn{2}{|c|}{ Control group $(n=20)$} & \multirow[b]{2}{*}{ Difference } & \multirow[b]{2}{*}{ Significance } \\
\hline & Mean & $S D$ & Mean & $S D$ & & \\
\hline \multicolumn{7}{|l|}{ Maxillary skeletal } \\
\hline SNA $\left(^{\circ}\right)$ & 0.2 & 1.8 & 1.0 & 4.3 & -0.8 & NS \\
\hline Point A-nasion perp (mm) & 0.2 & 1.7 & 1.0 & 4.0 & -0.8 & NS \\
\hline \multicolumn{7}{|l|}{ Mandibular skeletal } \\
\hline $\operatorname{SNB}\left({ }^{\circ}\right)$ & 1.1 & 1.3 & 1.2 & 3.2 & -0.1 & NS \\
\hline Pg-nasion perp (mm) & 2.6 & 2.2 & 2.3 & 6.2 & 0.3 & NS \\
\hline Co-Gn (mm) & 4.1 & 3.3 & 4.3 & 1.9 & -0.2 & NS \\
\hline \multicolumn{7}{|l|}{ Maxillary/mandibular } \\
\hline ANB $\left({ }^{\circ}\right)$ & -0.9 & 1.3 & -0.1 & 1.8 & -0.8 & NS \\
\hline Wits (mm) & -0.2 & 2.4 & 1.9 & 3.7 & -2.1 & NS \\
\hline \multicolumn{7}{|l|}{ Vertical skeletal } \\
\hline $\mathrm{FH}-\mathrm{PP}\left({ }^{\circ}\right)$ & 1.7 & 3.6 & -0.2 & 2.5 & 1.9 & * \\
\hline $\operatorname{MPA}\left({ }^{\circ}\right)$ & -0.6 & 3.3 & -0.5 & 3.6 & 0.1 & NS \\
\hline PP-mandibular plane $\left({ }^{\circ}\right)$ & -2.2 & 2.2 & -0.3 & 2.1 & -1.9 & $*$ \\
\hline ANS-Me (mm) & 0.9 & 1.6 & 1.9 & 1.5 & -1.0 & NS \\
\hline Co-Go (mm) & 1.8 & 2.8 & 2.1 & 2.2 & -0.3 & NS \\
\hline Gonial angle $\left({ }^{\circ}\right)$ & -1.7 & 2.7 & -1.2 & 3.1 & -0.5 & NS \\
\hline \multicolumn{7}{|l|}{ Interdental } \\
\hline Overjet (mm) & 0.3 & 2.2 & 1.0 & 1.3 & -0.1 & NS \\
\hline Overbite (mm) & 4.2 & 1.8 & 2.0 & 1.6 & 2.2 & $\dagger$ \\
\hline Interincisal angle $\left({ }^{\circ}\right)$ & 6.2 & 9.6 & -1.7 & 6.3 & 7.9 & NS \\
\hline Molar relationship (mm) & 0.5 & 1.8 & 0.1 & 1.8 & 0.4 & NS \\
\hline \multicolumn{7}{|l|}{ Maxillary dentoalveolar } \\
\hline U1-Point A vert (mm) & 0.5 & 1.8 & 1.1 & 1.4 & -0.6 & NS \\
\hline $\mathrm{U} 1-\mathrm{FH}\left({ }^{\circ}\right)$ & 0.3 & 6.1 & 1.2 & 5.6 & -0.9 & NS \\
\hline \multicolumn{7}{|l|}{ Mandibular dentoalveolar } \\
\hline L1-Point A Pg (mm) & -0.8 & 1.9 & 0.5 & 1.2 & -1.3 & NS \\
\hline L1-MPA ( $\left.{ }^{\circ}\right)$ & -3.7 & 5.8 & 2.0 & 2.8 & -5.7 & $\dagger$ \\
\hline
\end{tabular}

control group ( 15 subjects, $70 \%$; chi-square $=2.90 ; P=$ 0.036).

\section{DISCUSSION}

The specific features of this study were the following.

1. Patients were treated consecutively; they were included in the study regardless of treatment outcome. A posttreatment observation (T2) was obtained at the end of the active treatment with the $\mathrm{Q}-\mathrm{H} / \mathrm{C}$, and a long-term appraisal (T3) was available at least 5 years after treatment.

2. The control sample consisted of subjects with untreated anterior open bite, and they matched the $\mathrm{Q}-\mathrm{H} / \mathrm{C}$ group as to type of dentoskeletal malocclusion, age interval, skeletal maturation at different time points, and sex distribution (Table 1). Although historical control groups might have limitations, ${ }^{39}$ in our study the use of historical controls was due to the lack of ethical rationale to leave patients with anterior open bite untreated at the developmental period (early developmental phases) that is known as the optimal time for reestablishing normal dentoskeletal relationships. ${ }^{7,20}$ For the same ethical reasons, it would be impossible to collect a contemporary control group of subjects with untreated anterior open bite with an observation in the long term.

All subjects treated with the $\mathrm{Q}-\mathrm{H} / \mathrm{C}$ protocol ceased the thumb-sucking habit, as was noted in a previous study. ${ }^{17}$ No patient resumed thumb-sucking habits during the posttreatment period.

The results of the $\mathrm{T} 1$ to $\mathrm{T} 2$ interval showed no statistically significant differences between the 2 groups for the maxillary and mandibular skeletal components or the maxillomandibular relationships. Q- $\mathrm{H} / \mathrm{C}$ therapy produced on average about $2.0^{\circ}$ of downward rotation of the palatal plane with respect to the controls. As a result, intermaxillary divergence as measured by the angle between the palatal plane and the mandibular plane exhibited a significant mean reduction of about 
Table IV. Comparison of changes after treatment (T2-T3)

\begin{tabular}{|c|c|c|c|c|c|c|}
\hline \multirow[b]{2}{*}{ Cephalometric measurement } & \multicolumn{2}{|c|}{$Q-H / C$ group $(n=28)$} & \multicolumn{2}{|c|}{ Control group $(n=20)$} & \multirow[b]{2}{*}{ Difference } & \multirow[b]{2}{*}{ Significance } \\
\hline & Mean & $S D$ & Mean & $S D$ & & \\
\hline \multicolumn{7}{|l|}{ Maxillary skeletal } \\
\hline SNA $\left({ }^{\circ}\right)$ & -0.8 & 2.6 & 0.5 & 4.4 & -1.3 & NS \\
\hline Point A-nasion perp (mm) & -0.5 & 2.7 & 0.7 & 4.7 & -1.2 & NS \\
\hline \multicolumn{7}{|l|}{ Mandibular skeletal } \\
\hline $\operatorname{SNB}\left({ }^{\circ}\right)$ & 0.2 & 2.4 & 0.9 & 3.7 & -0.7 & NS \\
\hline Pg-nasion perp (mm) & 1.2 & 4.9 & 2.3 & 7.9 & -1.1 & NS \\
\hline Co-Gn (mm) & 10.1 & 6.4 & 11.5 & 3.2 & -1.4 & NS \\
\hline \multicolumn{7}{|l|}{ Maxillary/mandibular } \\
\hline ANB $\left({ }^{\circ}\right)$ & -1.0 & 2.0 & -0.5 & 1.6 & -0.5 & NS \\
\hline Wits (mm) & 0.8 & 4.2 & 0.4 & 4.9 & 0.4 & NS \\
\hline \multicolumn{7}{|l|}{ Vertical skeletal } \\
\hline $\mathrm{FH}-\mathrm{PP}\left({ }^{\circ}\right)$ & -0.6 & 3.5 & -0.5 & 1.9 & -0.1 & NS \\
\hline $\operatorname{MPA}\left({ }^{\circ}\right)$ & -2.7 & 3.0 & -2.3 & 2.5 & -0.4 & NS \\
\hline PP-mandibular plane $\left({ }^{\circ}\right)$ & -2.1 & 2.7 & -1.8 & 2.9 & -0.3 & NS \\
\hline ANS-Me (mm) & 5.4 & 3.8 & 5.7 & 2.5 & -0.3 & NS \\
\hline Co-Go (mm) & 5.4 & 5.2 & 6.5 & 3.3 & -1.1 & NS \\
\hline Gonial angle $\left({ }^{\circ}\right)$ & -4.3 & 3.1 & -3.2 & 3.3 & -1.1 & NS \\
\hline \multicolumn{7}{|l|}{ Interdental } \\
\hline Overjet (mm) & -0.9 & 2.0 & 0.0 & 2.0 & -0.9 & NS \\
\hline Overbite (mm) & 0.7 & 1.6 & 0.6 & 1.8 & 0.1 & NS \\
\hline Interincisal angle $\left({ }^{\circ}\right)$ & -2.1 & 12.0 & 1.5 & 7.0 & -3.6 & NS \\
\hline Molar relationship (mm) & 0.8 & 2.7 & 0.8 & 2.0 & 0.0 & NS \\
\hline \multicolumn{7}{|l|}{ Maxillary dentoalveolar } \\
\hline U1-Point A vert (mm) & 1.1 & 2.2 & 1.2 & 1.6 & -0.1 & NS \\
\hline $\mathrm{U} 1$ to $\mathrm{FH}\left({ }^{\circ}\right)$ & -1.2 & 7.1 & -0.5 & 4.6 & -0.7 & NS \\
\hline \multicolumn{7}{|l|}{ Mandibular dentoalveolar } \\
\hline L1-Point A Pg (mm) & 1.9 & 2.6 & 0.4 & 1.4 & 1.5 & NS \\
\hline L1-MPA $\left({ }^{\circ}\right)$ & 4.5 & 6.8 & 0.4 & 3.8 & 4.1 & NS \\
\hline
\end{tabular}

$N S$, Not significant; perp, perpendicular; Pg, pogonion; FH, Frankfort horizontal; $P P$, palatal plane; $U 1$, maxillary central incisor; vert, vertical; $L 1$, mandibular central incisor.

$2.0^{\circ}$ in the $\mathrm{Q}-\mathrm{H} / \mathrm{C}$ compared with the controls. This finding demonstrates that treatment with the $\mathrm{Q}-\mathrm{H} / \mathrm{C}$ produces favorable skeletal control of the vertical dimension in the short term.

These findings were similar to those described in a previous short-term study that reported a significantly greater downward rotation $\left(1.2^{\circ}\right)$ of the palatal plane associated with a significant reduction in the intermaxillary divergence $\left(-1.7^{\circ}\right)$ in the $\mathrm{Q}-\mathrm{H} / \mathrm{C}$ sample with respect to the controls at the end of the active treatment. ${ }^{17}$ On the other hand, our short-term treatment outcomes disagreed with those of Pedrin et $\mathrm{al}^{23}$ and Torres et al. ${ }^{24}$ The results of both studies showed that the effects of therapy primarily were dentoalveolar without significant changes in the skeletal maxillary and mandibular components. The initial mean amount of negative overbite (a measure of anterior dentoalveolar open bite) was $-3.3 \mathrm{~mm}$ in the $\mathrm{Q}-\mathrm{H} / \mathrm{C}$ group. The average increase in overbite $(4.2 \mathrm{~mm})$ during $\mathrm{Q}-\mathrm{H} / \mathrm{C}$ therapy overcorrected the amount of anterior open bite at $\mathrm{T} 2$. This value was statistically significant when compared with the control group.
This result agrees with the outcome at the end of active therapy with the same treatment protocol reported in a previous short-term study. ${ }^{17}$ Similarly, in the short-term results of Pedrin et al, ${ }^{23}$ the treated group showed a significant closure of the anterior open bite of $5.0 \mathrm{~mm}$, whereas Torres et $\mathrm{al}^{24}$ found an improvement in overbite of $3.9 \mathrm{~mm}$. In our study, a statistically significant lingual tipping $\left(-3.7^{\circ}\right)$ of the mandibular incisors to the mandibular plane contributed to the correction of overbite in the $\mathrm{Q}-\mathrm{H} / \mathrm{C}$ group. This treatment effect could be due to the normalization of function, such as elimination of tongue thrusting and interruption of sucking habits encouraged by the palatal crib. ${ }^{40}$

The statistical data can be accompanied by the analysis of individual data: 24 of 28 subjects showed positive overbites at T2. Therefore, in this study, we assessed the clinical effectiveness for the treatment protocol in approximately $86 \%$ of patients with dentoalveolar open bite at the end of active therapy. The failure of overbite correction in the other 4 subjects was attributable to their higher values for anterior open bite at $\mathrm{T} 1$. The prevalence rate for the success of $\mathrm{Q}-\mathrm{H} / \mathrm{C}$ therapy appears 
Table V. Comparison of long-term changes (T1-T3)

\begin{tabular}{|c|c|c|c|c|c|c|}
\hline \multirow[b]{2}{*}{ Cephalometric measurement } & \multicolumn{2}{|c|}{$Q-H / C$ group $(n=28)$} & \multicolumn{2}{|c|}{ Control group $(n=20)$} & \multirow[b]{2}{*}{ Difference } & \multirow[b]{2}{*}{ Significance } \\
\hline & Mean & $S D$ & Mean & $S D$ & & \\
\hline \multicolumn{7}{|l|}{ Maxillary skeletal } \\
\hline SNA $\left(^{\circ}\right)$ & -0.6 & 2.3 & 1.5 & 3.5 & -2.1 & NS \\
\hline Point A-nasion perp (mm) & -0.2 & 2.5 & 1.7 & 3.8 & -1.9 & NS \\
\hline \multicolumn{7}{|l|}{ Mandibular skeletal } \\
\hline $\operatorname{SNB}\left({ }^{\circ}\right)$ & 1.3 & 2.3 & 2.1 & 3.5 & -0.8 & NS \\
\hline Pg-nasion perp (mm) & 3.8 & 4.6 & 4.6 & 7.0 & -0.8 & NS \\
\hline Co-Gn (mm) & 14.2 & 6.1 & 15.8 & 4.4 & -1.6 & NS \\
\hline \multicolumn{7}{|l|}{ Maxillary/mandibular } \\
\hline ANB $\left(^{\circ}\right)$ & -1.9 & 1.9 & -0.6 & 1.7 & -1.3 & * \\
\hline Wits (mm) & 0.6 & 3.6 & 2.3 & 3.7 & -1.7 & NS \\
\hline \multicolumn{7}{|l|}{ Vertical skeletal } \\
\hline FH-PP $\left(^{\circ}\right)$ & 1.1 & 2.9 & -0.7 & 1.7 & 1.8 & * \\
\hline $\operatorname{MPA}\left({ }^{\circ}\right)$ & -3.2 & 2.7 & -2.8 & 3.7 & -0.4 & NS \\
\hline PP-mandibular plane $\left({ }^{\circ}\right)$ & -4.3 & 3.0 & -2.1 & 3.3 & -2.2 & $*$ \\
\hline ANS-Me (mm) & 6.3 & 3.3 & 7.7 & 3.1 & -1.4 & NS \\
\hline Co-Go (mm) & 7.1 & 5.1 & 8.5 & 3.9 & -1.4 & NS \\
\hline Gonial angle $\left({ }^{\circ}\right)$ & -6.0 & 4.2 & -4.5 & 3.6 & -1.5 & NS \\
\hline \multicolumn{7}{|l|}{ Interdental } \\
\hline Overjet (mm) & -0.6 & 2.7 & 0.9 & 2.0 & -1.5 & * \\
\hline Overbite (mm) & 4.9 & 2.0 & 2.8 & 1.7 & 2.1 & $\dagger$ \\
\hline Interincisal angle $\left({ }^{\circ}\right)$ & 4.1 & 12.7 & -0.2 & 8.4 & 4.3 & NS \\
\hline Molar relationship (mm) & 1.3 & 2.6 & 0.8 & 2.1 & 0.5 & NS \\
\hline \multicolumn{7}{|l|}{ Maxillary dentoalveolar } \\
\hline U1-Point A vert (mm) & 1.7 & 2.5 & 2.3 & 2.0 & -0.6 & NS \\
\hline $\mathrm{U} 1-\mathrm{FH}\left({ }^{\circ}\right)$ & -1.0 & 8.4 & 0.7 & 6.3 & -1.7 & NS \\
\hline \multicolumn{7}{|l|}{ Mandibular dentoalveolar } \\
\hline L1-Point A Pg (mm) & 1.0 & 2.3 & 0.9 & 1.8 & 0.1 & NS \\
\hline L1-MPA $\left({ }^{\circ}\right)$ & 0.8 & 6.1 & 2.4 & 4.9 & -1.6 & NS \\
\hline
\end{tabular}

$N S$, Not significant; perp, perpendicular; Pg, pogonion; $F H$, Frankfort horizontal; $P P$, palatal plane; $U 1$, maxillary central incisor; vert, vertical; $L 1$, mandibular central incisor.

${ }^{*} P<0.05 ;{ }^{\dagger} P<0.01$.

as a favorable result, and the prevalence is similar to the success rates reported in other studies on the early treatment of anterior open bite (80\% according Torres et $\mathrm{al}^{23}$ and Pedrin et $\mathrm{al}^{24} ; 90 \%$ according Cozza et $\left.\mathrm{a}^{28}\right)$. In our study, only 10 of the 20 subjects (50\%) of the control group showed spontaneous correction of anterior open bite. Comparison between prevalence rates of overbite correction at $\mathrm{T} 2$ was statistically significant, demonstrating the efficacy of treatment.

In the posttreatment period (T2-T3), no significant changes in the $\mathrm{Q}-\mathrm{H} / \mathrm{C}$ subjects over the controls were found. Therefore, no relapse in overbite was noted after active treatment.

The analysis of the overall results (Table V) showed that intermaxillary sagittal skeletal relationships exhibited favorable changes compared with the control group, with a decrease in the ANB angle of $1.3^{\circ}$. With respect to vertical skeletal features, the overall changes reflected the $\mathrm{T} 1$ to $\mathrm{T} 2$ changes. The outcomes of Q-H/C therapy produced a clinically significant downward rotation of the palatal plane of $1.8^{\circ}$, with a significant improvement in maxillomandibular divergence of $2.2^{\circ}$ in the $\mathrm{Q}-\mathrm{H} / \mathrm{C}$ group vs the control subjects. This favorable outcome deserves to be emphasized because of its clinical impact on dentoskeletal open bite: it contributes to the overall correction of anterior open bite significantly.

No previous clinical investigation has evaluated the effects of early correction of anterior open reevaluated at a 5-year follow-up with respect to a control sample with untreated anterior open bite. Only 1 study has addressed early correction with the Q-H/C appliance of anterior open bite in mixed-dentition patients with an adequate sample size and a control group. ${ }^{28}$ Evaluation of the results after 2 years of active treatment showed clinically significant improvements in both maxillomandibular vertical skeletal relationship $\left(2.5^{\circ}\right)$ and overbite $(2.7 \mathrm{~mm})$.

At a follow-up observation of 5 years, favorable changes in anterior dentoalveolar relationships were found. An improvement in the sagittal skeletal relationships (ANB, $-1.3^{\circ}$ in the $\mathrm{Q}-\mathrm{H} / \mathrm{C}$ vs the control) 
was associated with a significant reduction of $1.5 \mathrm{~mm}$ in overjet (-1.5 $\mathrm{mm}$ in the $\mathrm{Q}-\mathrm{H} / \mathrm{C}$ vs the control). The $\mathrm{Q}-\mathrm{H} /$ $C$ group also showed a significant improvement in overbite $(2.1 \mathrm{~mm})$ compared with the controls. The mean overbite increase in the $\mathrm{Q}-\mathrm{H} / \mathrm{C}$ group was $4.9 \mathrm{~mm}$, providing correction of the anterior open bite in 26 subjects, with a prevalence rate of $93 \%$. This value was significantly greater than that of the control group (70\%), and it also was greater than that reported in the previous study that assessed the clinical effectiveness for the same treatment protocol in approximately $85 \%$ of patients. ${ }^{28}$ The $23 \%$ gain in therapeutic effect can be considered clinically significant, since it was achieved with a relatively minimal burden on both the clinician and the patient. The appliances used were noncompliance devices; during fixed appliance therapy, no auxiliaries (eg, vertical or sagittal elastics) were applied. The results of this study showed that in the long term the elimination of oral habits permitted the normalization of function favoring improved facial growth in both the sagittal and vertical planes.

\section{CONCLUSIONS}

The treatment effects of the $\mathrm{Q}-\mathrm{H} / \mathrm{C}$ protocol in growing subjects with thumb-sucking habits and anterior open bite were compared with the growth changes in untreated subjects with the same dentoskeletal disharmony during a follow-up period of 5 years.

1. In the long term, the $\mathrm{Q}-\mathrm{H} / \mathrm{C}$ appliance led to successful outcomes in 93\% of the patients and a mean closure of the anterior open bite of about $5 \mathrm{~mm}$.

2. The $\mathrm{Q}-\mathrm{H} / \mathrm{C}$ protocol produced a clinically significant downward rotation of the palatal plane. This favorable outcome contributed significantly to the overall correction of the anterior open bite with an improvement in the vertical skeletal relationships.

\section{REFERENCES}

1. Worms FW, Meskin LH, Isaacson RJ. Open bite. Am J Orthod 1971; 59:589-95.

2. Ngan P, Fields HW. Open bite: a review of etiology and management. Pediatr Dent 1997;19:91-8.

3. Huang GJ, Justus R, Kennedy DB, Kokich VG. Stability of anterior open bite treated with crib therapy. Angle Orthod 1990;60:17-24.

4. Insoft MD, Hocevar RA, Gibbs CH. The nonsurgical treatment of a Class 11 open bite malocclusion. Am J Orthod Dentofacial Orthop 1996;1 10:598-605.

5. Chevitarese AB, Della Valle D, Moreira TC. Prevalence of malocclusion in 4-6 year old Brazilian children. J Clin Pediatr Dent 2002;27: 81-5.

6. Cozza P, Baccetti T, Franchi L, Mucedero M, Polimeni A. Sucking habits and facial hyperdivergency as risk factors for anterior open bite in the mixed dentition. Am J Orthod Dentofacial Orthop 2005; 128:517-9.

7. Heimer MV, Tornisiello KCR, Rosenblatt A. Non-nutritive sucking habits, dental malocclusions, and facial morphology in Brazilian children: a longitudinal study. Eur J Orthod 2008;30:580-5.

8. Cozza P, Baccetti T, Franchi L, Mucedero M, Polimeni A. Transverse features of subjects with sucking habits and facial hyperdivergency in the mixed dentition. Am J Orthod Dentofacial Orthop 2007;132:226-9.

9. Almeida RR, Ursi WJS. Anterior open bite: etiology and treatment. Oral Health 1990;80:27-31.

10. English JD. Early treatment of skeletal open bite malocclusions. Am J Orthod Dentofacial Orthop 2002;121:563-5.

11. Luzzi V, Guaragna M, lerardo G, Saccucci M, Consoli G, Vestri AR, et al. Malocclusions and non-nutritive sucking habits: a preliminary study. Prog Orthod 2011;12:114-8.

12. Isçan HN, Akkaya S, Elçin K. The effect of spring-loaded posterior bite block on the maxillo-facial morphology. Eur J Orthod 1992; 14:54-60.

13. Arat M, Iseri H. Orthodontic and orthopaedic approach in the treatment of skeletal open bite. Eur J Orthod 1992;14:207-15.

14. Kuster R, Ingervall B. The effect of treatment of skeletal open bite with two types of bite-blocks. Eur J Orthod 1992;14:489-99.

15. Weinbach JR, Smith RJ. Cephalometric changes during treatment with the open bite bionator. Am J Orthod Dentofacial Orthop 1992;101:367-74.

16. Schulz SO, McNamara JA Jr, Baccetti T, Franchi L. Treatment effects of bonded RME and vertical-pull chincup followed by fixed appliance in patients with increased vertical dimension. Am J Orthod Dentofacial Orthop 2005;128:326-36.

17. Cozza P, Baccetti T, Franchi L, McNamara JA Jr. Treatment effects of a modified quad-helix in patients with dentoskeletal open bites. Am J Orthod Dentofacial Orthop 2006;129:734-9.

18. Aznar T, Galan AF, Marin 1, Dominguez A. Dental arch diameters and relationships to oral habits. Angle Orthod 2006;76:441-5.

19. Haryett RD, Hansen FC, Davidson PO, Sandilands ML. Chronic thumb-sucking: the psychologic effects and the relative effectiveness of various methods of treatment. Am J Orthod 1967;53:569-85.

20. Parker JH. The interception of the open bite in the early growth period. Angle Orthod 1971;41:24-44.

21. Madiraju GS, Arika L. Effectiveness of appliance therapy in reducing overjet and open bite associated with thumb sucking habit. Minerva Stomatol 2011;60:333-8.

22. Haryett RD, Hansen FC, Davidson PO. Chronic thumb-sucking: a second report on treatment and its psychologic effects. Am J Orthod 1970;57:164-78.

23. Pedrin F, Almeida MR, Almeida RR, Almeida-Pedrin RR, Torres F. A prospective study of the treatment effects of a removable appliance with palatal crib combined with high-pull chincup therapy in anterior open-bite patients. Am J Orthod Dentofacial Orthop 2006;129:418-23.

24. Torres F, Almeida RR, de Almeida MR, Almeida-Pedrin RR, Pedrin F, Henriques JF. Anterior open bite treated with a palatal crib and high-pull chin cup therapy. A prospective randomized study. Eur J Orthod 2006;28:610-7.

25. Cozza P, Giancotti A, Rosignoli L. Use of a modified quad-helix in early interceptive treatment. J Clin Orthod 2000;34:473-6.

26. Cozza P, Baccetti T, Franchi L, Mucedero M. Comparison of 2 early treatment protocols for open-bite malocclusions. Am J Orthod Dentofacial Orthop 2007;132:743-7.

27. Giuntini V, Franchi L, Baccetti T, Mucedero M, Cozza P. Dentoskeletal changes associated with fixed and removable appliances with 
a crib in open-bite patients in the mixed dentition. Am J Orthod Dentofacial Orthop 2008;133:77-80.

28. Cozza P, Mucedero M, Baccetti T, Franchi L. Treatment and posttreatment effects of quad-helix/crib therapy of dentoskeletal open bite. Angle Orthod 2007;77:640-5.

29. Graber TM, Rakosi T, Petrovic A. Dentofacial orthopedics with functional appliances. St Louis: Mosby; 1997.

30. Baccetti T, Franchi L, McNamara JA Jr. The cervical vertebral maturation (CVM) method for the assessment of optimal treatment timing in dentofacial orthopedics. Semin Orthod 2005;11:119-29.

31. Rubin DB. Matching to remove bias in observational studies. Biometrics 1973;29:159-83.

32. Rosenbaum PR, Rubin DB. Constructing a control group using multivariate matched sampling methods that incorporate the propensity score. Am Stat 1985;39:33-8.
33. Thoemmes F. Propensity score matching in SPSS; 2012. Available at http://arxiv.org/ftp/arxiv/papers/1201/1201.6385.pdf.

34. Hansen BB, Bowers J. Covariate balance in simple, stratified and clustered comparative studies. Stat Sci 2008;23:219-36.

35. Sedgwick P. Parametric v non-parametric statistical tests. BMJ 2012;344:e1753.

36. Cohen J. A power primer. Psychol Bull 1992;112:155-9.

37. Houston WJ. The analysis of errors in orthodontic measurements. Am J Orthod 1983;83:382-90.

38. Dahlberg G. Statistical methods for medical and biological students. New York: Interscience Publications; 1940.

39. Pandis N. Use of controls in clinical trials. Am J Orthod Dentofacial Orthop 2012;141:250-1.

40. da Silva Filho OG, Gomes Goncalves RJ, Maia FA. Sucking habits: clinical management in dentistry. Pediatr Dent 1991;15: $137-56$. 